Article

\title{
Development of Multiplex PCR Assay for Screening of T6SS-5 Gene Cluster: The Burkholderia pseudomallei Virulence Factor
}

\author{
Noreafifah Semail ${ }^{1}$, Azian Harun ${ }^{1}$, Ismail Aziah ${ }^{2}{ }^{\mathbb{D}}$, Nik Mohd Noor Nik Zuraina ${ }^{1, *(\mathbb{C}}$ \\ and Zakuan Zainy Deris $1, * \mathbb{D}$ \\ 1 School of Medical Sciences, Universiti Sains Malaysia, Kubang Kerian 16150, Kelantan, Malaysia; \\ noreafifah93@gmail.com (N.S.); azian@usm.my (A.H.) \\ 2 Institute for Research in Molecular Medicine (INFORMM), Universiti Sains Malaysia, \\ Kubang Kerian 16150, Kelantan, Malaysia; aziahismail@usm.my \\ * Correspondence: nzuraina@usm.my (N.M.N.N.Z.); zakuan@usm.my (Z.Z.D.)
}

Citation: Semail, N.; Harun, A.; Aziah, I.; Nik Zuraina, N.M.N.; Deris, Z.Z. Development of Multiplex PCR Assay for Screening of T6SS-5 Gene Cluster: The Burkholderia pseudomallei Virulence Factor. Diagnostics 2022, 12, 562. https://doi.org/10.3390/ diagnostics12030562

Academic Editor: João Perdigão

Received: 24 January 2022

Accepted: 21 February 2022

Published: 23 February 2022

Publisher's Note: MDPI stays neutral with regard to jurisdictional claims in published maps and institutional affiliations.

Copyright: (C) 2022 by the authors. Licensee MDPI, Basel, Switzerland. This article is an open access article distributed under the terms and conditions of the Creative Commons Attribution (CC BY) license (https:// creativecommons.org/licenses/by/ $4.0 /)$.

\begin{abstract}
Despite the advanced understanding of the disease, melioidosis, an infection caused by Burkholderia pseudomallei, continues to be of global interest. The bacterial virulence factor, type six secretion system-5 (T6SS-5), in particular, is an essential factor for B. pseudomallei that is associated with internalization and intracellular survival of the pathogen. To detect the virulence gene cluster, this study has successfully developed a novel seven-gene (tssC-5, tagD-5, tss A-5, hcp-5, tss B-5, tssF-5, and $v g r$ G-5) multiplex PCR assay. The optimum annealing temperature for this assay ranged between 59 and $62{ }^{\circ} \mathrm{C}$. The limit of detection for this assay was $10^{3} \mathrm{CFU} / \mathrm{mL}$ for all genes, excluding tssF-5, which was found at $10^{5} \mathrm{CFU} / \mathrm{mL}$ of the bacterial concentration. In sensitivity and specificity tests, this multiplex assay was able to amplify all of the seven target genes from $93.8 \%(n=33 / 35)$ clinical and $100 \%(n=2 / 2)$ environmental isolates of B. pseudomallei. Whereas only four genes $(t s s C-5, \operatorname{tag} \mathrm{D}-5$, tssF-5, and $v g r G-5)$ were amplified from Bukholderia thailandesis, two genes (tagD-5 and tssB-5) were amplified from Bukholderia stagnalis, and zero target genes were amplified from Bukholderia ubonensis. No amplification of any genes was obtained when tested against isolated DNA from non-Bukholderia species ( $n=20)$, which include Staphylococcus aureus, Klebsiella pneumoniae, Enterococcus faecalis, and others. In conclusion, this multiplex PCR assay is sensitive, species-specific, rapid, and reliable to detect the virulent gene cluster T6SS-5 of B. pseudomallei.
\end{abstract}

Keywords: Burkholderia pseudomallei; T6SS-5; optimization; multiplex PCR

\section{Introduction}

Burkholderia pseudomallei is a gram-negative environmental saprophyte with high genetic diversity [1]. It is the causative agent of melioidosis, a neglected tropical and potentially fatal disease affecting both humans and animals. Melioidosis, a nominated Tier 1 select agent by the U.S. Centers for Disease Control and Prevention (CDC), is endemic in Southeast Asia and Northern Australia. It has expanded, and has been reported worldwide [2,3]. Every year, global melioidosis in humans is estimated at around 165,000 cases, with a mortality rate of over $50 \%$, a burden which is similar to that of measles [4,5]. In Malaysia, it is estimated that more than 2000 patients die due to melioidosis per year, which is much higher than the death caused by tuberculosis or dengue fever based on the reported incidence and mortality rate [6]. This indicates that the pathogen is highly virulent.

Type six secretion system-5 (T6SS-5) is one of the major virulence determinants for B. pseudomallei that has a central role in bacterial intracellular life cycle in mammalian host cells $[7,8]$. T6SS-5 is also crucial for the pathogenesis of systemic melioidosis [7,9-11]. T6SS- 5 has been constantly revealed as an important component for intercellular spread, multinucleated giant cell formation (MNGC), and virulence mechanisms. On the other 
hand, other T6SS clusters were reported to have different functions, especially in the persistence of this bacteria in its environmental niches. For instance, T6SS- 1 and T6SS- 4 are involved in inter-bacterial species competition and the acquisition of metal ions, respectively $[7,10,12]$.

The T6SS- 5 cluster comprises 13 genes and 2 accessory subunits that encode for the core components in the accumulation of a functional T6SS, and for the tags or regulator genes, respectively [12]. Although the function of these accessory subunits, four tag genes (tagA/B-5, $\operatorname{tag} \mathrm{B}-5$, $\operatorname{tag} \mathrm{C}-5$, and $\operatorname{tag} \mathrm{D}-5)$ and two vir AG regulator genes, is currently unknown, they are required for transcriptional activation of T6SS-5, and for the accurate assembly of the secretion apparatus during infection [13]. Of note, T6SS was induced throughout the melioidosis infection, highlighting its significant role to ensure B. pseudomallei persistence and replication in the cell cytosol [4]. Therefore, the determination of genetic variation in the virulence factors, particularly the T6SS- 5 gene cluster, is vital towards a better understanding of its correlation with the clinical presentations, relapse, and outcomes of melioidosis.

Research on B. pseudomallei has become of great interest, owing to the bio-threat potential of this pathogen, and an increasing awareness of melioidosis and its burden [14]. For that reason, the purpose of the present study was to develop a sensitive, speciesspecific, rapid, and reliable multiplex PCR assay for the detection of seven genes of the T6SS-5 virulence gene cluster. This assay might be useful for the early screening of potential virulence strains of B. pseudomallei from both clinical and environmental sources. In addition, this assay could facilitate in the laboratory diagnosis of melioidosis, since the pathogen is often misidentified with its closely related species.

\section{Materials and Methods}

\subsection{Bacterial Strains and Culture Conditions}

Archived B. pseudomallei clinical isolates and other reference bacterial strains used for the development of multiplex PCR in this study were obtained from the Department of Medical Microbiology and Parasitology, Hospital Universiti Sains Malaysia (HUSM). The environmental isolates were obtained from the Institute for Research in Molecular Medicine (INFORMM), USM, which include B. pesudomallei isolates and other Burkholderia species, namely Bukholderia thailandesis, Burkholderia ubonensis, and Burkholderia stagnalis. The clinical and environmental isolates were initially validated via a Vitek-2 automated instrumentation system. The isolates were sub-cultured onto a Mueller-Hinton ( $\mathrm{MH}$ ) agar plate, and incubated at $37^{\circ} \mathrm{C}$ for $48 \mathrm{~h}$. The pure colonies were used for further DNA isolation. For long-term storage, all isolates were stored at $-80^{\circ} \mathrm{C}$ in Brain Heart Infusion (BHI) broth containing $20 \%$ glycerol.

\subsection{Number of Colony Forming Units (CFUs) of Burkholderia pseudomallei}

B. pseudomallei was sub-cultured onto $\mathrm{MH}$ agar plates, and grown overnight at $37^{\circ} \mathrm{C}$. A single colony was collected and suspended in $5 \mathrm{~mL}$ MH broth. The culture was incubated at $37^{\circ} \mathrm{C}$ until the optical density reading at $600 \mathrm{~nm}(\mathrm{OD} 600)$ reached 1.0. Ten-fold serial dilution was performed from the culture, by which $100 \mu \mathrm{L}$ and $1 \mathrm{~mL}$ of each dilution factor was plated onto $\mathrm{MH}$ agar plates, and underwent DNA extraction by using a boiling method, respectively. The CFU of B. pseudomallei was counted following $24 \mathrm{~h}$ of incubation.

\subsection{Specific Primer Design}

All primers for the T6SS-5 gene cluster were designed using the National Center for Biotechnology Information (NCBI) Primer-BLAST, based on the available B. pseudomallei genome information (GenBank accession number: CP002834). In silico specificity of the primers was initially analyzed using the NCBI standard nucleotide-BLAST. The primers used in this study were synthesized by the Integrated DNA Technologies (IDT, Singapore). Primer sequences and their amplicon sizes are shown in Table 1. 
Table 1. Primers used for the optimization of the multiplex PCR assay.

\begin{tabular}{|c|c|c|c|c|}
\hline No. & Primer Pairs & Primer Sequences $\left(5^{\prime}\right.$ to $\left.3^{\prime}\right)$ & Target Gene & $\begin{array}{l}\text { Amplicon } \\
\text { Size (bp) }\end{array}$ \\
\hline \multirow{2}{*}{1} & tssC_F & GAGCTTCGCAGACTATCGCT & \multirow{2}{*}{$t s s C-5$} & \multirow{2}{*}{103} \\
\hline & tssC_R & GATCTCGCCCATCGATTCGT & & \\
\hline \multirow[b]{2}{*}{2} & tagD_F & ATGTCGGCGAAGATGATGGG & \multirow{2}{*}{$\operatorname{tag} \mathrm{D}-5$} & \multirow[b]{2}{*}{155} \\
\hline & tagD_R & ATCACTTTCTGCTGGCTCGG & & \\
\hline \multirow{2}{*}{3} & tssA_F & GCCGGATCAATCAAAGCCTG & \multirow{2}{*}{ tssA-5 } & \multirow{2}{*}{238} \\
\hline & tssA_R & TTGAGGTGGTTGAGGTGGTG & & \\
\hline \multirow[b]{2}{*}{4} & hcp_F & CCAGGGGGAAATCAAAGGCT & \multirow{2}{*}{$h c p-5$} & \multirow[b]{2}{*}{331} \\
\hline & hcp_R & GGGCGAGTATTGGTCCATGT & & \\
\hline \multirow{2}{*}{5} & tssB_F & GATCCGTCGCACCCAAAGAG & \multirow{2}{*}{ tssB-5 } & \multirow{2}{*}{406} \\
\hline & tssB_R & CTGCGAAAGCCGGGAATGTT & & \\
\hline \multirow{2}{*}{6} & tssF_F & GAACCTGCTGTTTCCGCACT & \multirow{2}{*}{$t s s \mathrm{~F}-5$} & \multirow{2}{*}{542} \\
\hline & tssF_R & CCAGCTCGACGAACAGGAAT & & \\
\hline \multirow{2}{*}{7} & vgrG_F & CACCTGCTGTTTCCCGATCT & \multirow{2}{*}{$\operatorname{vgrG}-5$} & \multirow{2}{*}{644} \\
\hline & vgrG_R & ATCGACACCGAGCACTTGAG & & \\
\hline
\end{tabular}

\subsection{DNA Template Preparation}

A bacterial DNA template was prepared by using a boiling method, where the bacterial colony was mixed with $200 \mu \mathrm{L}$ of distilled water by pipetting up and down several times. The mixture was boiled at $100{ }^{\circ} \mathrm{C}$ for $10 \mathrm{~min}$, and was centrifuged at $13,000 \times g$ for $5 \mathrm{~min}$. The supernatant was collected into a clean micro-centrifuge tube, and stored at $-20^{\circ} \mathrm{C}$.

\subsection{PCR Amplification}

For the development of multiplex PCR, each $20 \mu \mathrm{L}$ reaction contained $5 \mu \mathrm{L}$ of MyTaq Red reaction buffer, and $0.3 \mu \mathrm{L}$ of MyTaq Red DNA polymerase (Bioline Reagents Ltd., London, $\mathrm{UK}), 4.7 \mu \mathrm{L}$ of $\mathrm{dH}_{2} \mathrm{O}, 0.5 \mu \mathrm{L}$ of each primer pair, and $3 \mu \mathrm{L}$ of DNA template. A PCR run was performed in a thermal cycler machine (Eppendorf, Hamburg, Germany). The PCR cycling condition was set up with an initial heating step at $95^{\circ} \mathrm{C}$ for $5 \mathrm{~min}$, plus 30 repeating cycles consisting of denaturation at $95^{\circ} \mathrm{C}$ for $30 \mathrm{~s}$, annealing at $61^{\circ} \mathrm{C}$ for $30 \mathrm{~s}$, and elongation at $72{ }^{\circ} \mathrm{C}$ for $1 \mathrm{~min}$. A final elongation step at $72{ }^{\circ} \mathrm{C}$ for 5 min was added to complete the polymerization process.

\subsection{Agarose Gel Electrophoresis}

After PCR amplification, the PCR products were analyzed using $2 \%$ agarose gel in $0.5 \times$ TBE electrophoresis buffer. Gel electrophoresis was run at 80 volts for 90 min to separate the target bands. The DNA fragment in agarose gel was visualized and photographed under the ultraviolet light of a G-Box image analyzer (Syngene, Frederick, MD, USA).

\subsection{Optimization of Multiplex PCR}

The multiplex PCR was optimized to ensure appropriate amplification, and to obtain the greatest intensity of the PCR bands. The primers concentration was optimized by reducing the concentration of $t s s \mathrm{~A}-5$, tss C-5, and $t a g \mathrm{D}-5$ from $10 \mu \mathrm{m}$ of the initial concentration to 5.0, $2.5,1.25$, and $0.625 \mu \mathrm{m}$. The annealing temperature, ranging from $52{ }^{\circ} \mathrm{C}$ to $62{ }^{\circ} \mathrm{C}$, was also optimized using a gradient program on a thermal cycler.

\subsection{Analytical Sensitivity of the Multiplex PCR Assay}

Analytical sensitivity of the multiplex PCR assay was evaluated by using a ten-fold serial dilution of $B$. pseudomallei overnight culture. DNA was prepared from each dilution by using the boiling method described earlier. Three microliters of DNA from each dilution were used as the template for evaluating the limit detection of the multiplex PCR assay. The PCR was run under the conditions described above. 


\subsection{Accuracy Test of the Multiplex PCR Assay}

To validate the efficiency of the multiplex PCR assay, extracted DNA from B. pesudomallei clinical isolates $(n=32)$ and environmental isolates of Burkholderia species $(n=11)$ were subjected to the multiplex PCR assay. The environmental Burkholderia species were two B. pseudomallei, two B. thailandesis, one B. ubonensis, and six Burkholderia stagnalis isolates. The specificity of the multiplex PCR assays in this study were verified by using different bacterial species, which include Staphylococcus aureus ATCC 25923, Klebsiella pneumoniae ATCC 70063, Enterecoccus faecalis ATCC 29212, Pseudomonas aeruginosa ATCC 27853, Neisseria meningitidis ATCC 13090, Vibrio parahaemolyticus ATCC 17802, Escherichia coli ATCC 35218, Streptococcus Group A and B, Staphylococcus epidermidis, Salmonella enterica serovar Typhimurium, Streptococcus viridans, Stenotrophomonas maltophilia, Helicobacter pylori, Vibrio cholerae, Salmonella sp., and Proteus mirabilis.

\section{Results}

\subsection{Number of Colony Forming Units (CFU) of B. pseudomallei Clinical Isolate}

Colony forming units were used to estimate the number of viable cells of $B$. pseudomallei clinical isolate. At the OD600 of 1.0, the plate counting result showed that the B. pseudomallei culture was equivalent to $1.62 \times 10^{11} \mathrm{CFU} / \mathrm{mL}$.

\subsection{Amplification of T6SS-5 Genes}

All of the designed primers for T6SS- 5 genes successfully amplified $103 \mathrm{bp}$ of tssC-5 gene, $155 \mathrm{bp}$ of $\operatorname{tag\mathrm {D}}-5$ gene, $230 \mathrm{bp}$ of $t s s \mathrm{~A}-5$ gene, $331 \mathrm{bp}$ of $h c p-5$ gene, $406 \mathrm{bp}$ of $t s s \mathrm{~B}-5$ gene, $542 \mathrm{bp}$ of $t s s \mathrm{~F}-5$ gene, and $627 \mathrm{bp}$ of $v g r \mathrm{G}-5$ gene (Figure 1 , lanes 1 to 7 , respectively). All of the seven genes amplified using this multiplex PCR assay are shown in Figure 1 (lane 8). The PCR products were divergent to one another according to their discrete sizes produced on the gel electrophoresis.

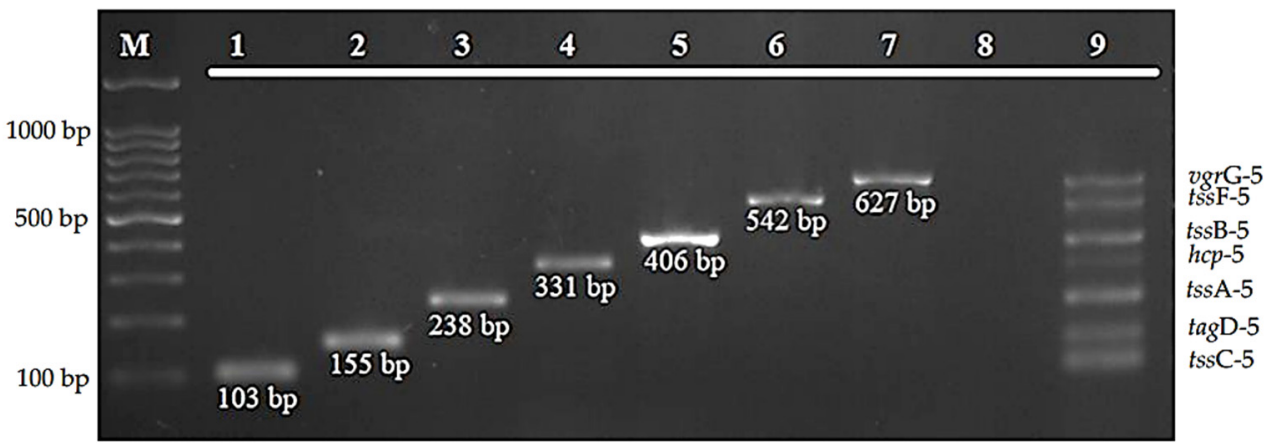

Figure 1. Amplification of the target genes by the developed multiplex PCR assay. Lane M: $100 \mathrm{bp}$ DNA marker; lanes 1-7: monoplex PCR of tssC-5, tagD-5, tssA-5, hcp-5, tssB-5, tssF-5, vgrG-5, respectively; lane 8: negative control; and lane 9: multiple bands of all seven genes.

\subsection{Optimization of the Multiplex PCR}

The optimal primer concentration and annealing temperature of the multiplex PCR assay were determined to ensure an appropriate amplification and uniform intensity of all of the target genes simultaneously. Of the different concentration tested $(5.0,2.5,1.25$, and $0.625 \mu \mathrm{m})$, the primer concentration of $5.0 \mu \mathrm{m}$ was chosen as the optimal concentration for tss A-5, tss C-5, and tagD-5, as shown in Figure 2. 


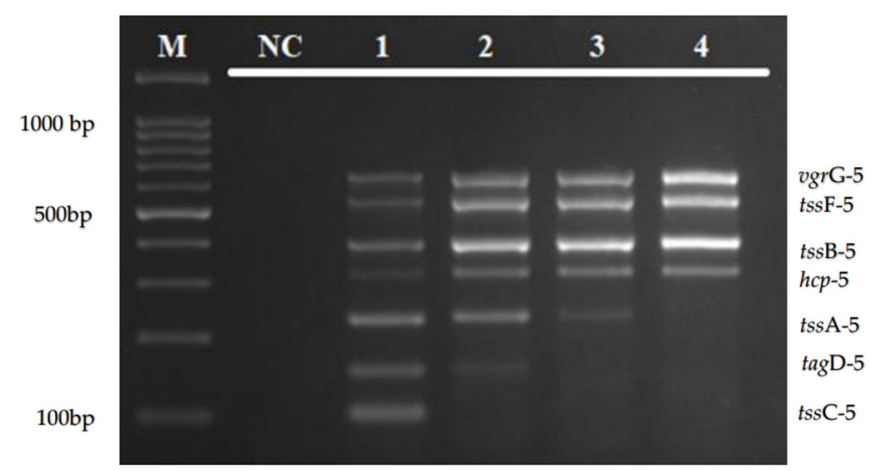

Figure 2. Optimization of primer concentration for $t s s \mathrm{~A}-5$, tssC-5, and tagD-5 primers. Lane M: $100 \mathrm{bp}$ DNA marker; lane NC: negative control; lane 1: $5.0 \mu \mathrm{m}$; lane 2: $2.5 \mu \mathrm{m}$; lane 3: $1.25 \mu \mathrm{m}$; and lane 4: $0.625 \mu \mathrm{m}$.

The optimization of the annealing temperature using gradient PCR in Figure 3 shows that an annealing temperature of $52-62{ }^{\circ} \mathrm{C}$ was able to amplify all of the targeted genes. In this study, the intensity of all target bands was observed to be clearer at higher sets of temperature $\left(59^{\circ} \mathrm{C}\right.$ to $\left.62^{\circ} \mathrm{C}\right)$. Hence, the annealing temperature at $61^{\circ} \mathrm{C}$ was chosen to run the multiplex PCR assay.

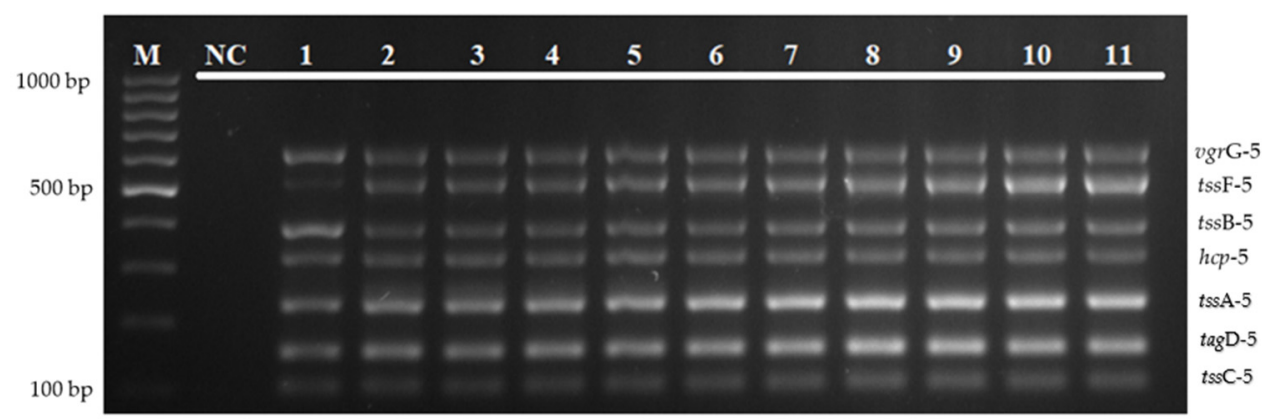

Figure 3. Agarose gel electrophoresis for the optimization of annealing temperature using gradient PCR. The optimization of annealing temperature for the multiplex PCR assay was set up from $52{ }^{\circ} \mathrm{C}$ to $62^{\circ} \mathrm{C}$. Lane M: $100 \mathrm{bp}$ DNA ladder; lane NC: negative control; and lanes 1-11: annealing temperature from $52{ }^{\circ} \mathrm{C}$ to $62{ }^{\circ} \mathrm{C}$, respectively.

\subsection{Specificity of the Multiplex PCR}

The specificity of the multiplex PCR assay was evaluated on B. pseudomallei isolates and other bacterial strains, which include S. aureus, K. pneumoniae, E. faecalis, P. aeruginosa, V. parahaemolyticus, N. meningitidis, E. coli, Streptococcus Group A and B, S. epidermidis, S. enterica serovar thypimurium, and $S$. viridans. As shown in Figure 4, no amplification was obtained from non-Burkholderia strains tested with the specific primer pairs in detecting T6SS-5 genes.

\subsection{Analytic Sensitivity of the Multiplex PCR}

In this study, to determine the analytical sensitivity, lysate DNA prepared from 10-fold serial dilutions of $B$. pseudomallei overnight culture $(\mathrm{OD} 600=1)$ were used as the template in the developed multiplex PCR assay. As shown in Figure 5, the detection limit of the multiplex PCR assay was $10^{3} \mathrm{CFU} / \mathrm{mL}$. Most of the T6SS- 5 target amplicons can be detected at $10^{3} \mathrm{CFU} / \mathrm{mL}$. However, the lowest detection limit for tssF-5 gene was $10^{5} \mathrm{CFU} / \mathrm{mL}$, which is two-log higher than other targets. 


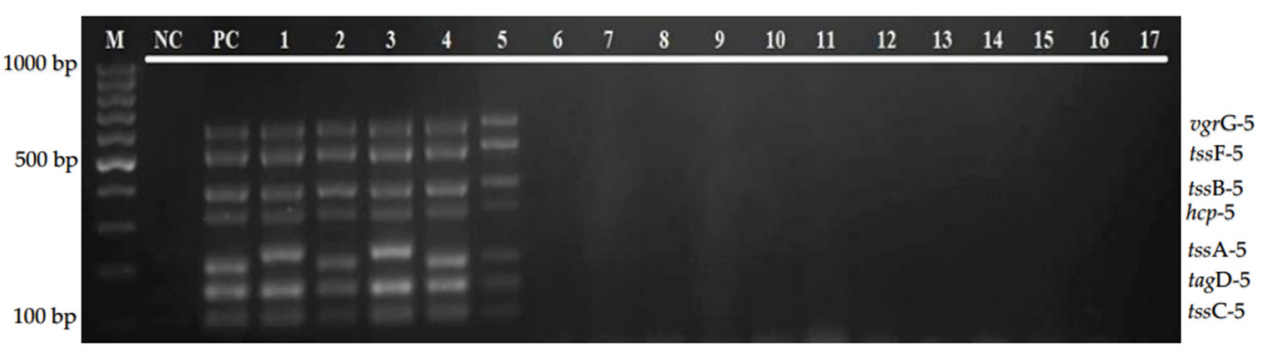

(a)

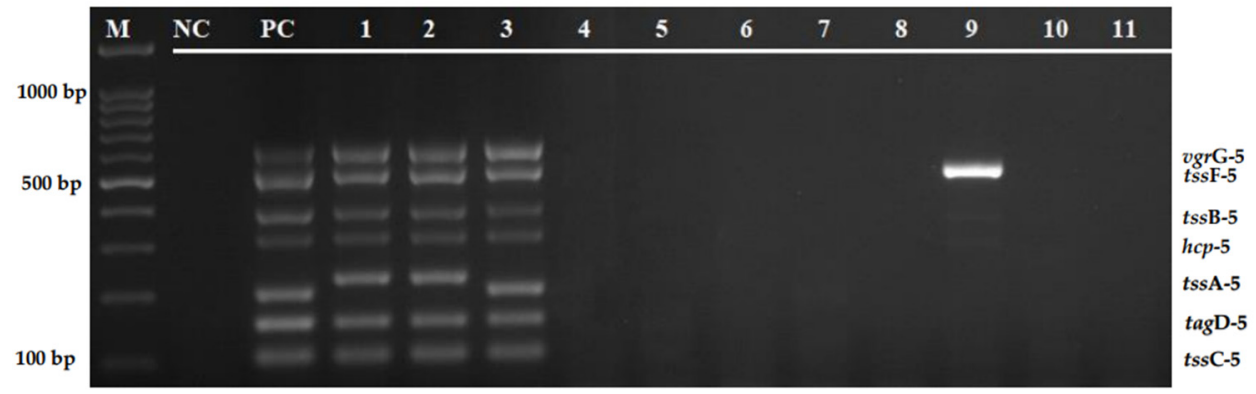

(b)

Figure 4. (a) Specificity evaluation of the multiplex PCR assay on B. pseudomallei isolates and other bacterial strains. Lane M: 100 bp DNA ladder; lane NC: negative control; lane PC: positive control; lanes 1-5: B. pseudomallei isolates; and lanes 6-17: S. aureus ATCC 25923, K. pneumoniae ATCC 70063, E. faecalis ATCC 29212, P. aeruginosa ATCC 27853, V. parahaemolyticus ATCC 17802, N. meningitidis 13090, E. coli ATCC 35218, Streptococcus Group A, S. epidermidis, S. enterica serovar Thypimurium, Streptococcus Group B, and S. viridans, respectively. (b) Specificity evaluation of the multiplex PCR assay on B. pseudomallei isolates and other bacterial strains. Lane M: 100 bp DNA ladder; lane NC: negative control; lane PC: positive control; lanes 1-3: B. pseudomallei isolates; lanes 4-6: S. maltophilia isolates; lanes 7-11: H. pylori, E. faecalis, V. cholerae, Salmonella sp., and P. mirabilis, respectively.

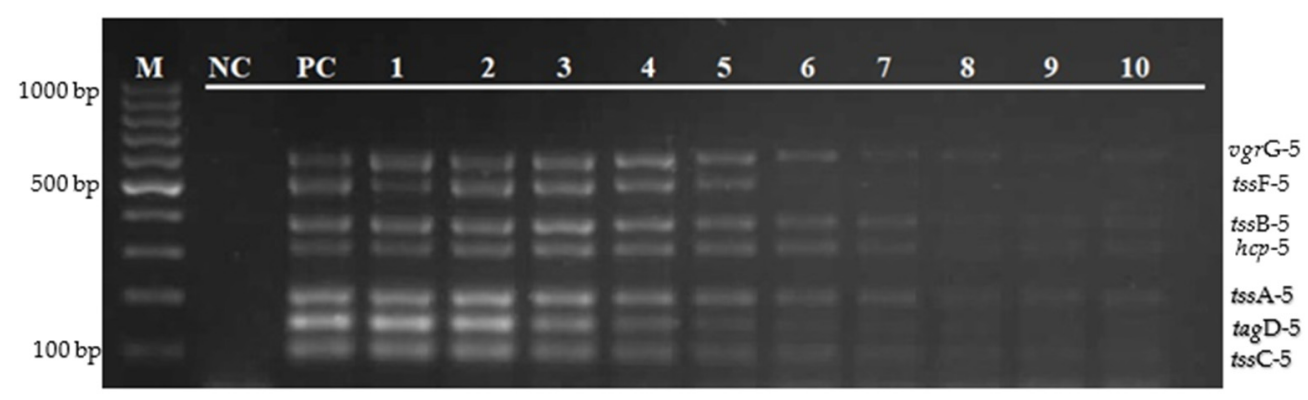

Figure 5. Analytical sensitivity of multiplex PCR assay in the presence of $10^{9}$ to $10^{0} \mathrm{CFU} / \mathrm{mL}$ of B. pseudomallei concentrations. Lane M: 100 bp DNA ladder; lane NC: negative control; lane PC: positive control; and lanes $1-10$ represent $10^{9}$ to $10^{0} \mathrm{CFU} / \mathrm{mL}$ lysate of $B$. pseudomallei, respectively.

\subsection{Evaluation of Multiplex PCR Using Clinical and Environmental Isolates}

The efficiency of the multiplex PCR assay was evaluated on 32 clinical isolates of B. pseudomallei and 11 environmental isolates (two B. pseudomallei, and nine other Burkholderia species). When tested on clinical isolates, this multiplex assay was able to amplify all of the 7 genes in 30 isolates. However, two isolates (lanes 16 and 26) were found positive for only five and three genes, respectively. This study also found a variation in the size of these genes, especially tssA-5 (Figure $6 a, b)$. The evaluation of this multiplex assay against the environmental isolates indicated similar results, in which all of the target genes are present in both B. pseudomallei isolates. However, only four of the target genes (tssC-5, tagD-5, tssF-5, and $\operatorname{vgr} \mathrm{G}-5$ ) were detected from both $B$. thailandesis, two genes (tagD-5 and 
tssB-5) were detected from two of six B. stagnalis, and no single gene was detected from B. ubonensis (Figure 7).

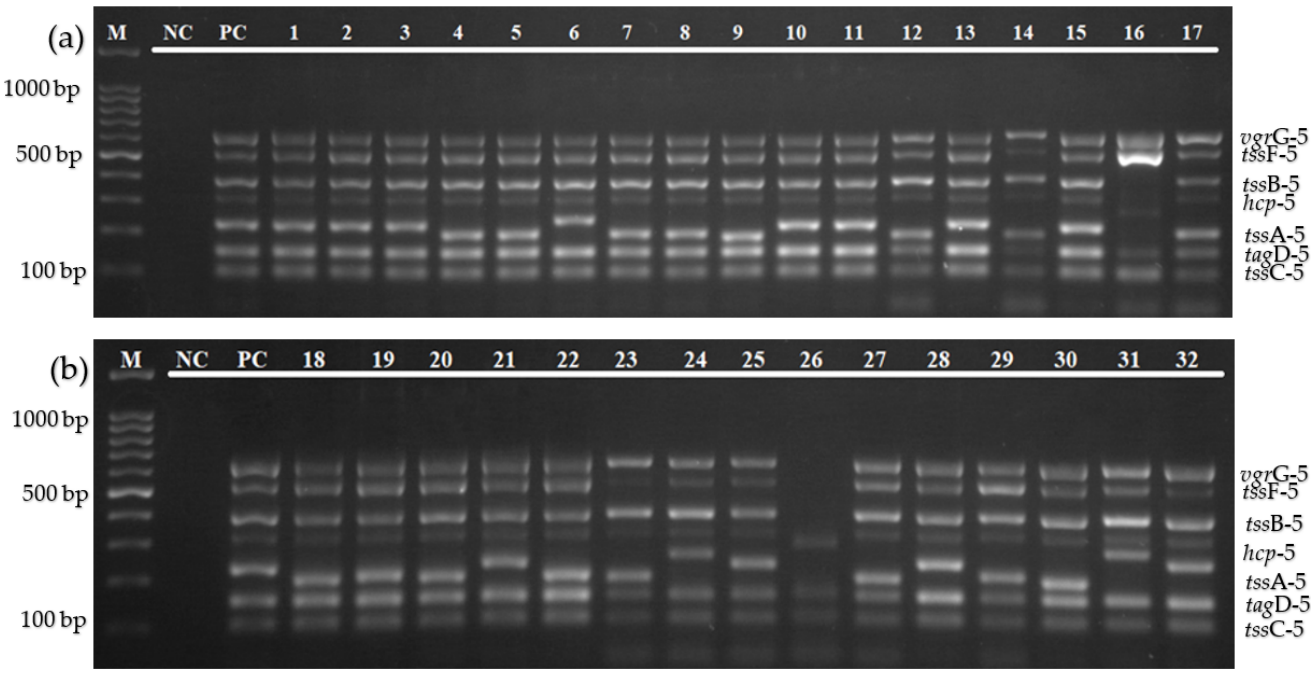

Figure 6. $(\mathbf{a}, \mathbf{b})$ : Evaluation of multiplex PCR using clinical samples. Lane M: 100 bp DNA ladder; NC: negative control; PC: positive control; and lanes 1-32 represent clinical isolates of B. pseudomallei.

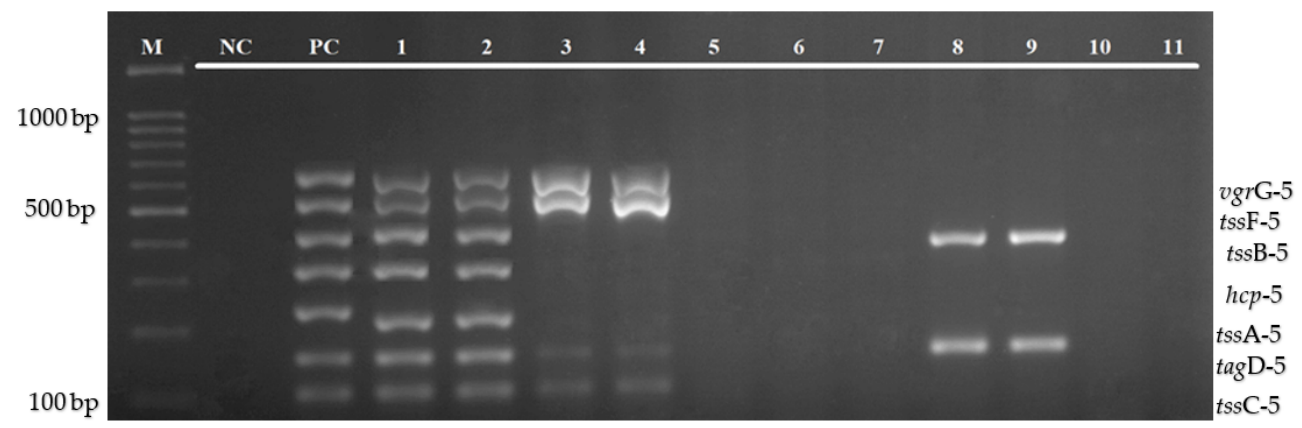

Figure 7. Evaluation of multiplex PCR using environmental isolates of B. pseudomallei and other species of Bukrholderia. Lane M: 100bp DNA Ladder; NC: negative control; PC: positive control; lanes 1-2: B. pseudomallei; lanes 3-4: B. thailandesis; lane 5: B. ubonensis; and lanes 6-11: B. stagnalis.

\section{Discussion}

In recent years, the development of specific and sensitive molecular methods for the simultaneous detection and differentiation of Burkholderia species has been the subject of growing interest [15-17]. However, to our knowledge, this present study is the first study on the development of a molecular-based assay targeting the virulence genes from the Type 6 Secretion Systems-5 (T6SS-5) gene cluster in B. pseudomallei. This study has successfully developed a multiplex PCR assay for the screening of seven genes of the T6SS-5 gene cluster from pure colonies of both clinical and environmental isolates of B. pseudomallei in a single tube reaction. The developed multiplex PCR assay consists of seven pairs of primers, MyTaq Red reaction buffer, MyTaq Red DNA polymerase, and $\mathrm{dH}_{2} \mathrm{O}$, in which target amplicon ranging from 103-644 bp were developed for the multiplex PCR assay.

Primer design, as well as primer specificity, is the first and most critical step in the process of establishing a successful molecular detection assay. Therefore, to enable for correct amplification of all of the target genes, all of the primer pairs were designed to suit the following conditions: having an equal range of melting temperature $\left(57-60{ }^{\circ} \mathrm{C}\right)$ and GC content (50-60\%), minimal formation of dimers or hairpin structures (delta $\mathrm{G}$ value more than $-9.0 \mathrm{kcal} / \mathrm{mole})$, and the ability to target the conserved sequence regions $[17,18]$. In 
this study, the multiplex PCR was developed to target specific genes of the T6SS-5 virulence gene cluster, which include $t s s \mathrm{C}-5, \operatorname{tag} \mathrm{D}-5, t s s \mathrm{~A}-5, h c p-5, t s s \mathrm{~B}-5, t s s \mathrm{~F}-5$, and $\operatorname{vgr} \mathrm{G}-5$ genes.

Most of these genes are located in the cytoplasmic (inner membrane) of B. pseudomallei, and have important roles in the bacterial pathogenesis. The hemolysin co-regulated protein (Hcp) is a hallmark and a critical component of a functional T6SS, as it facilitates translocation of small effector proteins into the host cell membrane by creating tubules $[9,11]$. Valine-glycine repeat protein (Vgr) is necessary for MNGC formation or cell fusions, and consequently leads to intercellular spread of the bacterial infection $[19,20]$. It penetrates the target cell through its needle-shaped $\beta$-helical domain [20]. In addition, tss $\mathrm{A}$, tss $\mathrm{B}$, and tss $C$ are involved in the assembly of the baseplate and the sheath-tube, contractile sheath polymerization, and intracellular replication and formation of MNGC, respectively.

It is notable that setting up monoplex PCR reactions in detecting different genes of T6SS-5 gene clusters at a single time is tiresome. Using this multiplex PCR assay, detection and screening of targeted genes of the T6SS-5 gene cluster in clinical and environmental isolates of B. pseudomallei would be easier and faster. In comparison to a monoplex PCR that requires lengthy procedures for multiple targets, a multiplex PCR assay could minimize the tedious steps of calculation, preparation, optimization, and pipetting, which can reduce the time consumed for the PCR work, and consequently reduce the chances for carry-over contamination [21]. An approximate duration of four hours is needed to obtain the results of the multiplex PCR in one run, starting from the PCR set-up to the final step of the interpretation using gel electrophoresis.

The annealing temperature of the multiplex PCR assay was optimized using a gradient thermal cycler to test the specificity and sensitivity of primer-template binding. The optimization of the gradient annealing temperature in Figure 2 shows that an annealing temperature of $52-62{ }^{\circ} \mathrm{C}$ was able to amplify all of the targeted genes, and $61^{\circ} \mathrm{C}$ was chosen as the optimal temperature for this multiplex amplification. Besides that, the developed multiplex PCR assay was highly specific. As shown in Figure $4 a, b$, there was no target gene amplification observed when tested with other bacterial pathogens, except for a band which is complementary to the amplicon size of the tssF-5 gene in $V$. cholerae isolate.

The limit of detection of a multiplex PCR assay depends on the product size and the combination of multiple primers in a single tube, which might affect the effectiveness of the PCR amplifications [22,23]. In most cases, the sensitivity of multiplex PCR assay is often reduced with the increased number of target genes in the assay [24], which is contrary to our result. The limit of detection of this multiplex PCR assay was $1.62 \times 10^{3} \mathrm{CFU} / \mathrm{mL}$ for most of the targeted genes. However, the analytical sensitivity for the $t s s \mathrm{~F}-5$ gene $\left(1.62 \times 10^{5} \mathrm{CFU} / \mathrm{mL}\right)$ was two-log lower than other targets. Most of the target genes in this multiplex PCR assay could be detected at low amounts of bacterial concentration $\left(10^{3} \mathrm{CFU} / \mathrm{mL}\right)$, thus showing that this assay has a comparable sensitivity to other in-house PCR $\left(10^{5} \mathrm{CFU} / \mathrm{mL}\right)$, lateral flow-recombinase polymerase amplification $\left(10^{3} \mathrm{CFU} / \mathrm{mL}\right)$, and TaqMan Real-Time PCR $\left(10^{3} \mathrm{CFU} / \mathrm{mL}\right)$ assays from previous studies $[25,26]$.

Furthermore, the multiplex PCR assay was evaluated using clinical and environmental isolates of B. pseudomallei and other Burkholderia species, as shown in Figure 6a,b and Figure 7. Based on the result, of the total 35 B. pseudomallei clinical isolates, this multiplex PCR was able to detect all of the target genes from 33 isolates. Interestingly, this study has observed that there was a variation in the size of the tssA-5 gene that will be further analyzed using a DNA sequencing method. For the environmental isolates, both isolates of B. pseudomallei can detect all of the seven T6SS-5 targeted genes. However, only four of the target genes, which include $t s s \mathrm{C}-5, \operatorname{tag} \mathrm{D}-5, \operatorname{tss} \mathrm{F}-5$, and $\operatorname{vgr} \mathrm{G}-5$, can be detected from $B$. thailandesis. This assay could not detect any of the target genes from B. ubonensis. However, tagD-5 and tssB-5 genes can be detected from two isolates of B. stagnalis. This result indicates that not all genes in the T6SS-5 gene cluster are present in all Burkholderia species, which might be due to the lesser pathogenicity of other species. One limitation of this study is that the sensitivity, specificity, and evaluation of the clinical and environmental isolates were tested on a limited number of isolates. An inadequate number of B. pseudomallei environ- 
mental isolates was available from our collection. In future accuracy tests, the sample size and type of organism should be expanded, and diagnostic evaluation of this assay directly from clinical specimens should be included for an extensive screening. Other Burkholderia species, such as Burkholderia mallei, Burkholderia cepacia, and Burkholderia vietnamiensis, and non-Burkholderia species, particularly Chromobacterium violaceum, which can cause an infection with similar symptoms to melioidosis, should also be included for a more comprehensive analysis. Apart from that, further studies are also needed to develop an assay consisting of the whole set of genes in the T6SS-5 gene cluster to elaborate the function of this particular virulence factor in B. pseudomallei.

\section{Conclusions}

In conclusion, this study has successfully developed a novel, sensitive, species-specific, rapid, and reliable multiplex PCR assay for the detection of the T6SS-5 virulence gene cluster of B. pseudomallei from pure colonies. This assay is convenient and time-saving, which is applicable in many places compared to other expensive techniques, such as realtime PCR, next generation sequencing, and micro-array, which have been used to identify this bacterium. It is also relevant for the screening of B. pseudomallei strains from both clinical and environmental sources. Moreover, the developed PCR assay can be used to identify and distinguish B. pseudomallei species from other bacterial strains by a simple technique. This study also provided an interesting insight to the further understanding of the variation of T6SS-5 genes among B. pseudomallei, and the uniqueness of certain genes that can only be found in B. pseudomallei species.

Author Contributions: Conceptualization, Z.Z.D. and N.M.N.N.Z.; methodology, N.S., N.M.N.N.Z.; validation, N.S., Z.Z.D. and N.M.N.N.Z.; writing-original draft preparation; N.S., writing-review and editing, N.S., Z.Z.D., N.M.N.N.Z., A.H., I.A.; supervision, Z.Z.D., A.H., I.A. All authors have read and agreed to the published version of the manuscript.

Funding: This research was funded and supported by Ministry of Higher Education Malaysia for Fundamental Research Grant Scheme with Project Code: FRGS/1/2019/SKK11/USM/02/5.

Institutional Review Board Statement: This study was approved by the Institutional Review Board of the Human Research Ethics Committee, USM (Registration Number: USM/JEPeM/19090528).

Informed Consent Statement: Not applicable.

Data Availability Statement: Not applicable.

Acknowledgments: The authors would like to thank the Department of Medical Microbiology and Parasitology, School of Medical Sciences, Universiti Sains Malaysia, for providing the bacterial strains and facilities used in this study.

Conflicts of Interest: The authors declare no conflict of interest.

\section{References}

1. Seng, R.; Saiprom, N.; Phunpang, R.; Baltazar, C.J.; Boontawee, S.; Thodthasri, T. Prevalence and genetic diversity of Burkholderia pseudomallei isolates in the environment near a patient's residence in Northeast Thailand. PLoS Negl. Trop. Dis. 2019, 13, e0007348. [CrossRef] [PubMed]

2. Wagar, E. Bioterrorism and the role of the clinical microbiology laboratory. Clin. Microbiol. Rev. 2016, 29, 175-189. [CrossRef] [PubMed]

3. Dance, D.A. Melioidosis as an emerging global problem. Acta Trop. 2000, 74, 115-119. [CrossRef]

4. Arushothy, R.; Amran, F.; Samsuddin, N.; Ahmad, N.; Nathan, S. Multi locus sequence typing of clinical Burkholderia pseudomallei isolates from Malaysia. PLoS Negl. Trop. Dis. 2020, 14, e008979. [CrossRef] [PubMed]

5. Limmathurotsakul, D.; Golding, N.; Dance, D.A.; Messina, J.P.; Pigott, D.M.; Moyes, C.L. Predicted global distribution of Burkholderia pseudomallei and burden of melioidosis. Nat. Microbiol. 2016, 1, 1-5. [CrossRef] [PubMed]

6. Nathan, S.; Chieng, S.; Kingsley, P.V.; Mohan, A.; Podin, Y.; Ooi, M.H. Melioidosis in Malaysia: Incidence, clinical challenges, and advances in understanding pathogenesis. Trop. Med. Infect. Dis. 2018, 3, 25. [CrossRef]

7. Schwarz, S.; West, T.E.; Boyer, F.; Chiang, W.C.; Carl, M.A.; Hood, R.D. Burkholderia type VI secretion systems have distinct roles in eukaryotic and bacterial cell interactions. PLoS Pathog. 2010, 6, e1001068. [CrossRef] 
8. French, C.T.; Toesca, I.J.; Wu, T.H.; Teslaa, T.; Beaty, S.M.; Wong, W. Dissection of the Burkholderia intracellular life cycle using a photothermal nanoblade. Proc. Natl. Acad. Sci. USA 2011, 108, 12095-12100. [CrossRef]

9. Pilatz, S.; Breitbach, K.; Hein, N.; Fehlhaber, B.; Schulze, J.; Brenneke, B. Identification of Burkholderia pseudomallei genes required for the intracellular life cycle and in vivo virulence. Infect. Immun. 2006, 74, 3576-3586. [CrossRef]

10. Burtnick, M.N.; Brett, P.J.; Harding, S.V.; Ngugi, S.A.; Ribot, W.J.; Chantratita, N. The cluster 1 type VI secretion system is a major virulence determinant in Burkholderia pseudomallei. Infect. Immun. 2011, 79, 1512-1525. [CrossRef]

11. Wong, J.; Chen, Y.; Gan, Y.H. Host cytosolic glutathione sensing by a membrane histidine kinase activates the type VI secretion system in an intracellular bacterium. Cell Host Microbe 2015, 18, 38-48. [CrossRef] [PubMed]

12. Lennings, J.; West, T.E.; Schwarz, S. The Burkholderia type VI secretion system 5: Composition, regulation and role in virulence. Front. Microbiol. 2018, 9, 3339. [CrossRef] [PubMed]

13. Zoued, A.; Brunet, Y.R.; Durand, E.; Aschtgen, M.S.; Logger, L.; Douzi, B. Architecture and assembly of the Type VI secretion system. Biochim. Biophys. Acta (BBA) Mol. Cell Res. 2014, 1843, 1664-1673. [CrossRef] [PubMed]

14. Wiersinga, W.J.; Virk, H.S.; Torres, A.G.; Currie, B.J.; Peacock, S.J.; Dance, D.A. Melioidosis. Nat. Rev. Dis. Primers 2018, 4, 1-22. [CrossRef]

15. Lowe, C.W.; Satterfield, B.A.; Nelson, D.B.; Thiriot, J.D.; Heder, M.J.; March, J.K. A Quadruplex Real-Time PCR Assay for the Rapid Detection and Differentiation of the Most Relevant Members of the B. pseudomallei Complex: B. mallei, B. pseudomallei, and B. thailandensis. PLOS ONE 2016, 11, e0164006.

16. Lee, M.A.; Wang, D.; Yap, E.H. Detection and differentiation of Burkholderia pseudomallei, Burkholderia mallei and Burkholderia thailandensis by multiplex PCR. FEMS Immunol. Med. Microbiol. 2005, 43, 413-417. [CrossRef]

17. Koh, S.F.; Tay, S.T.; Sermswan, R.; Wongratanacheewin, S.; Chua, K.H.; Puthucheary, S.D. Development of a multiplex PCR assay for rapid identification of Burkholderia pseudomallei, Burkholderia thailandensis, Burkholderia mallei and Burkholderia cepacia complex. J. Microbiol. Methods 2012, 90, 305-308. [CrossRef]

18. Deng, X.; Zhang, J.; Su, J.; Liu, H.; Cong, Y.; Zhang, L. A multiplex PCR method for the simultaneous detection of three viruses associated with canine viral enteric infections. Arch. Virol. 2018, 163, 2133-2138. [CrossRef]

19. Toesca, I.J.; French, C.T.; Miller, J.F. The Type VI secretion system spike protein VgrG5 mediates membrane fusion during intercellular spread by pseudomallei group Burkholderia species. Infect. Immun. 2014, 82, 1436-1444. [CrossRef]

20. Schwarz, S.; Singh, P.; Robertson, J.D.; LeRoux, M.; Skerrett, S.J.; Goodlett, D.R. VgrG-5 is a Burkholderia type VI secretion system-exported protein required for multinucleated giant cell formation and virulence. Infect. Immun. 2014, 82, 1445-1452. [CrossRef]

21. Nik Zuraina, N.M.N.; Goni, M.D.; Amalina, K.N.; Hasan, H.; Mohamad, S.; Suraiya, S. Thermostable Heptaplex PCR Assay for the Detection of Six Respiratory Bacterial Pathogens. Diagnostics 2021, 11, 753. [CrossRef] [PubMed]

22. Henegariu, O.; Heerema, N.; Dlouhy, S.; Vance, G.; Vogt, P. Multiplex PCR: Critical parameters and step-by-step protocol Biotechniques 1997, 23, 504-511. [CrossRef] [PubMed]

23. Sea-Liang, N.; Sereemaspun, A.; Patarakul, K.; Gaywee, J.; Rodkvamtook, W.; Srisawat, N. Development of multiplex PCR for neglected infectious diseases. PLoS Negl. Trop. Dis. 2019, 13, e0007440. [CrossRef] [PubMed]

24. Wang, Z.; Zuo, J.; Gong, J.; Hu, J.; Jiang, W.; Mi, R. Development of a multiplex PCR assay for the simultaneous and rapid detection of six pathogenic bacteria in poultry. Amb. Express 2019, 9, 1-11. [CrossRef] [PubMed]

25. Zueter, A.M.; Harun, A.B. Development and Validation of Conventional PCR for the Detection of the sctQ Gene. Jordan J. Biol. Sci. 2018, 11, 435-439.

26. Peng, Y.; Zheng, X.; Kan, B.; Li, W.; Zhang, W.; Jiang, T. Rapid detection of Burkholderia pseudomallei with a lateral flow recombinase polymerase amplification assay. PLoS ONE 2019, 14, e0213416. [CrossRef] 